\title{
Regulación de la donación de gametos y embriones en las técnicas de reproducción humana asistida: ¿anónima o abierta?
}

Rosa Verónica Esparza-Pérez

Universidad Nacional de Educación a Distancia, Madrid, España

\section{Resumen}

El uso de gametos y embriones donados en técnicas de reproducción humana asistida hace necesario examinar intereses que implican consideraciones éticas y jurídicas relevantes, y estos incluyen los derechos de autonomía y privacidad de los padres de intención, el derecho a la privacidad de los donantes y el derecho de los menores a conocer su origen genético. En este artículo se exponen argumentos para considerar políticas de mayor apertura para la obtención de información de los donantes en aras de proteger el interés superior del niño y la niña a conocer sus orígenes genéticos. Concluye con la problemática en México, donde desde hace varios años se realizan técnicas de reproducción humana asistida con gametos donados, sin embargo, debido a la ausencia de una normatividad que regule estos procedimientos, cada establecimiento impone sus criterios para el funcionamiento de sus programas.

PALABRAS CLAVE: Identidad genética. Interés superior del niño y la niña. Donación de gametos y embriones.

\begin{abstract}
The use of donated gametes and embryos in assisted reproduction techniques (ART) makes it necessary to examine interests that involve relevant ethical and legal considerations, which include the autonomy and privacy rights of the intended parents, donors' right to privacy and the right of the minors to know their genetic origin. This article presents arguments to consider policies of more openness to obtain information from donors in order to protect the child's best interest in knowing his/her genetic origins. It concludes with the situation in Mexico, where ART has been carried out with donated gametes since several years ago; however, due to the absence of regulations to control these procedures, each establishment imposes its own criteria for the operation of its programs.
\end{abstract}

KEY WORDS: Genetic identity. Child's best interest. Gamete and embryo donation.

Correspondencia:

Rosa Verónica Esparza-Pérez

E-mail: esparzaveronica@hotmail.com
Fecha de recepción: 23-02-2018

Fecha de aceptación: 28-08-2018

DOI: 10.24875/GMM. 18004248
Gac Med Mex. 2019;155:3-14

Disponible en PubMed www.gacetamedicademexico.com 


\section{Introducción}

Antes de la aparición de las técnicas de reproducción asistida (TRHA) solo existía la procreación por medios naturales, a través del coito; por ello, necesariamente lo biológico comprendía lo genético, ante la imposibilidad de disociarlo. Ahora, con los procedimientos de reproducción humana asistida, lo biológico ya no comprende forzosamente lo genético; ni lo genético, lo biológico. Actualmente el aporte puede ser exclusivamente genético, es el caso de las TRHA heterólogas, con material genético proveniente de donadores.

Las TRHA incluyen el manejo in vitro de ovocitos humanos, esperma y embriones para el propósito de la reproducción. Esto incluye, pero no se limita, fertilización in vitro, transferencia de embriones, inyección intracitoplásmica, biopsia embrionaria, prueba genética de preimplantación, eclosión asistida, transferencia intrafalopiana de gametos, transferencia intrafalopiana de cigotos, gametos y crioconservación de embriones, semen, donación de ovocitos y embriones, y ciclos de portadoras gestacionales. Por lo tanto, las TRHA no incluye a la inseminación artificial utilizando semen de la pareja de la mujer o de un donador. ${ }^{1}$

El desarrollo de las TRHA y la disposición de las personas a donar sus gametos y embriones para el tratamiento de otros ha hecho posible que muchas personas puedan tener descendencia. Tan solo en el Reino Unido, entre 1992 y 2009 fueron concebidos 31000 niños con gametos donados. ${ }^{2}$ En Estados Unidos, en los últimos 20 años, los nacimientos por donaciones de gametos aumentaron de 30000 a 60 000, sin embargo, estas cifras son solo estimaciones debido al limitado sistema de registros. ${ }^{3}$

A medida que la cesión de células germinales se vuelve más común, se hace necesario examinar intereses que implican consideraciones éticas y jurídicas relevantes, y estos incluyen los derechos de autonomía y privacidad de los padres de intención, el derecho a la privacidad de los donantes y el derecho de los menores a conocer su origen genético. ${ }^{4}$ En este punto es necesario tener en cuenta que las expresiones origen genético y origen biológico no son exactamente equivalentes: la primera se refiere a la llamada herencia genética, o patrimonio genético; el extraordinario progreso de la técnica ha favorecido el acceso al conocimiento de este origen desde que, cuando existe material indubitado, la probabilidad de llegar a la información exacta es hoy muy elevada. La expresión origen biológico abarca, además del dato genético, otros aspectos comprensivos de la vida (bio) de una persona, tales como los vínculos afectivos trabados con otras personas (abuelos, hermanos, etcétera), que integran su propia historia. ${ }^{4}$

Uno de los temas más debatidos al momento de legislar ha sido, y sigue siendo, el relativo a si las TRHA heterólogas deberían realizarse en secreto y anónimamente, o bien, con mayor apertura en aras de garantizar el derecho de los hijos nacidos mediante estas donaciones a conocer su origen genético, sin intención de cuestionar la filiación ya determinada. Si bien, el anonimato sigue siendo la práctica más frecuente en el mundo, ha habido una tendencia política hacia un enfoque más abierto en la obtención de información de los donantes, con la intención de compartirla con los futuros padres y para la divulgación potencial a la futura descendencia. ${ }^{5}$

Las razones de esta transición hacia una mayor apertura respecto a la información de los donadores están basadas, entre otras, en el derecho a conocer la identidad genética como parte del derecho a la identidad primordialmente - aunque no exclusivamente - de los menores. Los casos vinculados con los derechos de las niñas y los niños son complejos debido a que esta rama del derecho debe regirse bajo principios propios, en ocasiones, diferentes a los del derecho en general, como el principio que protege el interés superior del niño. ${ }^{6}$ El interés superior del niño y la niña, implica que el desarrollo de estos y el ejercicio pleno de sus derechos deben ser considerados como criterios rectores para la elaboración de normas y la aplicación de estas en todos los órdenes relativos a su vida. ${ }^{7}$ El derecho a la identidad desde la perspectiva de los derechos de la niña y el niño debe abordarse específicamente, así pues, en este artículo se aborda el derecho a la identidad genética de los niños nacidos proveniente de donantes, desde la perspectiva de los derechos del niño y la niña.

La última parte de este artículo expone el caso particular de México, donde la expansión de los centros en los que se practican procedimientos de reproducción asistida y el elevado número de niños que han sido concebidos con ayuda de estos revelan la existencia de un mercado global. Pese a ello, el legislador federal, hasta este momento, no ha adoptado una normatividad que prevea los aspectos generales del acceso y provisión de los servicios. Debido a la ausencia de reglas claras, los responsables de las clínicas, tanto públicas como privadas, operan sus programas de donación de gametos y embriones con 
base en sus propios criterios, normas académicas 0 lineamientos emitidos en consenso por expertos, que, independientemente del profesionalismo y calidad en la atención médica, deja a los usuarios en situación de vulnerabilidad e inseguridad jurídica.

\section{Conceptos identidad, datos genéticos e identidad genética}

\section{Identidad}

La Real Academia Española define el concepto de identidad como "conjunto de rasgos propios de un individuo o de una colectividad que los caracterizan frente a los demás. Conciencia que una persona tiene de ser ella misma y distinta a las demás". Algunos autores la han definido como el "conjunto de atributos y características que permiten individualizar a la persona en sociedad [...] es todo aquello que hace que cada cual sea uno mismo y no otro". ${ }^{8}$ En el concepto de identidad puede incluirse tanto el derecho a conocer el origen genético como otros elementos necesarios para la determinación de la relación filial. Para este artículo, el aspecto que nos interesa será el derecho a la identidad genética.

\section{Datos genéticos}

Nuestro material genético nos acompaña desde los primeros estadios de la vida y hasta la muerte. Al realizar una serie de técnicas metodológicas es posible la extracción de cierta información específica, actualmente denominada "datos genéticos humanos". 9 La potencialidad aplicativa de los datos genéticos se ha convertido en un factor relevante para diversas actividades relacionadas con la salud y la asistencia sanitaria. Los datos genéticos pueden indicar predisposiciones genéticas de los individuos - no necesariamente de carácter patológico- de importancia futura e incierta, como proporcionar información útil para el desarrollo de investigaciones científicas encaminadas a la detección y cura de enfermedades y aportar información de relevancia que puede trascender el ámbito individual para afectar a la descendencia; pueden brindar datos para el futuro, aunque la relevancia de esa información no se conozca en el momento de extraer las muestras biológicas. ${ }^{10}$

La Declaración Internacional de Datos Genéticos Humanos de la UNESCO de 2003 entiende por datos genéticos lo siguiente: "toda información sobre las características hereditarias de las personas, obtenida por análisis de ácidos nucleicos u otros análisis científicos". Por su parte, en la Recomendación (97) 5 del Consejo de Europa se les define como "todos los datos, con independencia de su tipo, que se refieren a las características hereditarias de una persona $o$ al modelo de herencia de estas características de un grupo de la misma familia".

Por ello, las técnicas de ADN revelan el carácter único de cada persona y los datos que pueden obtenerse a través de su análisis transparentan ámbitos sensibles de la vida privada y de la propia realidad física de la persona. Los datos genéticos humanos tienen condiciones especiales que los distinguen de otros, puesto que repercuten no solo en la persona de cuyos datos se trate, sino también son importantes para el conjunto de la familia, en especial para su descendencia; por ello, se considera necesario adoptar medidas para tutelar los derechos que pueden verse comprometidos con estas técnicas, entre estos el derecho a la identidad genética.

\section{Identidad genética}

Desde la identificación del ADN, la genética constituye un tipo de intimidad. Los descubrimientos en torno a este ácido han permitido alcanzar un conocimiento preciso de nuestra identidad genética. La revelación de la intimidad genética puede afectar no solo al sujeto de cuya intimidad se trate, también puede interferir en sus descendientes y otros miembros de su grupo familiar con quienes comparte ciertos rasgos genéticos. ${ }^{9}$

La Declaración Internacional sobre Datos Genéticos Humanos y de Derechos Humanos recomienda a los Estados esforzarse por proteger la privacidad de las personas y la confidencialidad de los datos genéticos humanos asociados con una persona, una familia o, en su caso, un grupo identificable. Este instrumento propone algunas reglas en que estos datos deben ser tratados, una de ellas es que los datos genéticos de una persona identificable no deben ser revelados o ser accesibles a terceras partes, excepto con el consentimiento de la persona en cuestión.

Como todos los derechos, los derechos a la privacidad y confidencialidad de los datos genéticos admiten limitantes y pueden restringirse en atención a otros derechos y bienes jurídicos,$^{10}$ sería el caso de los hijos nacidos mediante procedimientos de reproducción asistida con material genético donado, en quienes conocer esta información colabora a que 
tengan conocimiento de su origen genético. Se considera que predomina el interés superior del menor. ${ }^{9}$

Salvo casos en los que predomine un interés superior, los datos genéticos de una persona identificable no deberán ser dados a conocer a terceros, excepto en los supuestos previstos en el derecho interno o cuando se cuente con el consentimiento de la persona a la que pertenece esa información.

\section{El derecho a conocer el origen genético}

El avance en la medicina genómica y sus implicaciones en la salud hacen que cada vez sea más importante el conocimiento del origen genético como medio para conocer la predisposición a desarrollar enfermedades potencialmente prevenibles, (por ejemplo, modificando el estilo de vida) ${ }^{9}$ y para impedir el riesgo de matrimonio o procreaciones con un pariente consanguíneo. ${ }^{6}$ El levantamiento del anonimato en las TRHA heterólogas se apoya en la idea de que la protección del interés superior de los niños a conocer sus orígenes debe guiar el enfoque jurídico. En ese sentido, Irène Théry aclara: ${ }^{11}$

\begin{abstract}
No quiere decir que se conceda más importancia a los intereses psicológicos de un individuo-niño que a los de otros individuos-adultos, sino más bien que se define jurídicamente la donación en reproducción asistida como un acto social que adquiere su sentido y su valor particulares por el hecho de que todas las partes implicadas contractualmente en el engendramiento deben concurrir para organizar esta en beneficio de aquel que, una vez nacido, será considerado como persona jurídica, sujeto de derechos.
\end{abstract}

El interés superior del niño se define aquí, en términos jurídicos, negativamente: como el derecho de no privar a priori y definitivamente de información sobre la identidad de las personas que le han permitido nacer, y de forma positiva este derecho puede formularse como tener la posibilidad de decidir si se quiere conocer 0 ignorar la identidad del donante. ${ }^{11}$ Pero el derecho a no saber, como una manifestación de libertad frente a saber, implica que ya se tiene conocimiento del hecho que genera este derecho, que ya se sabe. ${ }^{12}$

A nivel internacional, el principio del interés superior del niño $0^{6,13}$ se reconoce en el artículo 3.1. de la Convención sobre los Derechos del Niño, el cual establece:

En todas las medidas concernientes a los niños que tomen las instituciones públicas o privadas de bienestar social, los tribunales, las autoridades administrativas o los órganos legislativos, una consideración primordial a que se atenderá será el interés superior del niño.
Si bien, la Convención sobre los Derechos del Niño no promueve de forma específica el derecho del niño al conocimiento de su origen, en su artículo 7 establece que el niño tendrá derecho, en la medida de lo posible, a conocer a sus padres y que es responsabilidad de los Estados parte velar por la aplicación de estos derechos, de conformidad con su legislación nacional y las obligaciones que hayan contraído en virtud de los instrumentos internacionales pertinentes en esta esfera. Por su parte, el artículo 8 establece que los Estados parte se comprometen a respetar el derecho del niño a preservar su identidad, incluidos la nacionalidad, el nombre y las relaciones familiares de conformidad con la ley, sin injerencias ilícitas y que cuando un niño sea privado ilegalmente de algunos de los elementos de su identidad o de todos ellos, los Estados parte deberán prestar la asistencia y protección apropiadas con miras a restablecer rápidamente su identidad.

El Comité de las Naciones Unidas sobre Derechos del Niño, a cargo de supervisar la aplicación de la Convención sobre los Derechos del Niño, ha declarado la conveniencia de permitir el acceso a los orígenes genéticos, por ejemplo, en 2002 se pronunció respecto a la legislación británica y señaló: ${ }^{14}$

El Comité expresa preocupación porque los hijos nacidos fuera de matrimonio, los hijos adoptados o los nacidos mediante fertilización médicamente asistida no tengan derecho a conocer la identidad de sus progenitores biológicos.

Recomendó al Estado adoptar las medidas para que todos los niños, independientemente de las circunstancias de su nacimiento, puedan conseguir, en la medida de lo posible, información sobre la identidad de sus progenitores. ${ }^{14}$

En el marco del sistema interamericano de protección de los derechos humanos, el reconocimiento del derecho a la identidad se vincula estrechamente con la desaparición forzada de personas. Son muchos los casos resueltos por la Corte Interamericana de Derechos Humanos en los cuales, si bien se aclara que no es un derecho expresamente previsto en la Convención Interamericana; su reconocimiento deriva de la interpretación sistemática de los artículos 18 (derecho al nombre) y 17 (derecho a la protección de la familia). ${ }^{15,16}$ Pese a que, hasta este momento, la Corte Interamericana de Derechos Humanos no ha tenido oportunidad de pronunciarse sobre casos en los que se invoque el derecho a la identidad de una persona concebida mediante gametos o embriones donados, sí existe una protección del derecho a la identidad en el marco de la Convención Americana. 
En el ámbito europeo, a través de varios precedentes (entre los que destacan "Gaskin vs. Reino Unido", del 7 de julio de 1989, y "Mikulic vs. Croacia", del 7 de febrero de 2002 y "Ebru et Tayfun Engin Çolak vs. Turquía", del 30 de mayo de 2006), el Tribunal Europeo de Derechos Humanos ha concluido que el respeto por la vida privada requiere que las personas puedan ser capaces de establecer detalles sobre su propia identidad como seres humanos y que, en principio, no pueden ser obstruidas por las autoridades para obtener esa información básica sin causa justificada. También ha reconocido el interés, protegido por el Convenio Europeo de Derechos Humanos, de obtener informaciones necesarias para el descubrimiento de la verdad sobre un aspecto importante de su identidad, por ejemplo, la identidad de sus progenitores.

\section{Posiciones en el derecho comparado}

La regulación y práctica de técnicas reproductivas con donación de gametos se aborda con particularidades en los diferentes países. ${ }^{17}$ Este repaso a algunas regulaciones en el derecho comparado no pretende ser exhaustivo, el objetivo no es entrar en la complejidad de las diferentes normativas, sino únicamente documentar las tendencias a nivel global sobre el levantamiento del anonimato en las donaciones.

\section{Legislaciones que reconocen el derecho del hijo a conocer la identidad del donante}

En 1984, Suecia modificó su ley para conceder a los niños nacidos de una donación de esperma el derecho a conocer la identidad de su donante una vez que alcancen la madurez suficiente. La ley austríaca consagra el derecho del niño a partir de los 14 años, a tener conocimiento de la identidad del donante. En Finlandia, la ley permite al concebido mediante gametos $0 \mathrm{em}$ briones donados, a partir de los 18 años, conocer la identidad del donante. En los Países Bajos, después de 15 años de debates, las donaciones dejaron de ser anónimas desde junio de 2004. ${ }^{11}$ En Noruega, cualquier persona que haya nacido como resultado de la reproducción asistida utilizando esperma donado tiene el derecho a la información sobre la identidad del donante de esperma, a la edad de 18 años. ${ }^{18}$ Nueva Zelanda desde 2004 suprimió el anonimato de donantes de gametos y creó un registro para el establecimiento voluntario de contactos entre donantes, receptores e hijos nacidos por reproducción asistida a fin de responder, en la medida de lo posible, a las demandas de información relativas a los casos de donaciones previas a la ley. ${ }^{11}$ Por su parte, Holanda, en el año 2000, aprobó una ley en la que solamente se permiten las donaciones no anónimas y las clínicas tienen la obligación de reclutar donadores no anónimos. Por último, en el Reino Unido, ${ }^{19,20}$ a partir de una consulta pública y una posterior reforma en 2004, la Human Fertilisation and Embryology Act permite que los concebidos a partir del 1 de abril de 2005 mediante semen, óvulos o embriones donados soliciten información identificativa sobre los donantes, una vez cumplidos los 18 años.

En los países latinoamericanos, donde la regla general todavía es el anonimato del donante, Uruguay y Argentina han legislado en sentido contrario. Ninguno, sin embargo, reconoce un derecho del concebido a conocer sus orígenes genéticos, sino tan solo la posibilidad de solicitar el acceso a esa información por la vía judicial.

\section{Legislaciones que prevén una política de doble vía}

Algunas legislaciones permiten al donante acogerse a las modalidades anónima o identificable de la donación y a los usuarios de las técnicas, utilizar gametos procedentes de uno u otro tipo de donante, o bien, condicionan el acceso a la identidad de los donantes a su consentimiento escrito. A esta política se le conoce como double track (doble vía) ${ }^{21}$ y quienes la defienden, argumentan que tiene como ventajas la autorregulación, el bienestar de la familia en su conjunto y el reconocimiento de la pluralidad moral.

En contra de este modelo podría argumentarse que subordina el derecho a conocer los orígenes al ejercicio que haga o no el donante de su derecho a la privacidad e intimidad, otorgando mayor peso a este que al derecho de las personas a conocer sus orígenes genéticos. ${ }^{8,21}$ Este sistema es el adoptado por varios territorios de Estados Unidos, donde la mayor parte de los Estados no han regulado esta cuestión y la decisión sobre el carácter anónimo o no de las donaciones depende de cada centro médico y de las preferencias de los usuarios.

\section{Legislaciones que protegen el anonimato del donante}

La legislación española mantiene el anonimato de donantes a pesar de los cambios producidos en el 
entorno europeo*; la ley solo permite conocer datos no identificativos del donante. Así, de acuerdo con el precepto, la regla general es que la información sobre el donante que puede obtener el concebido mediante gametos donados, por sí o por sus representantes legales, se restringe a datos muy básicos que no incluyan su identidad.

En Francia, el anonimato es regla general. El Ministerio de Sanidad propuso en 2010 su supresión parcial y la propuesta fue rechazada, pero un informe oficial concluyó que el Registro Civil debería permitir al hijo conocer, una vez alcanzada la mayoría de edad, la forma en que fue concebido para que, si así lo desea, solicite conocer al o los donantes. Ahora bien, el informe supedita esa posibilidad al consentimiento del donante, puesto que sostiene que el anonimato es compatible con su derecho a la vida privada y familiar..$^{15}$

Por otra parte, en Italia, la legislación en materia de reproducción asistida inicialmente prohibía la fecundación heteróloga, aspecto que finalmente fue declarado inconstitucional por la Corte Costituzionale italiana, en el fallo 162 del 9 de abril de 2014 (https:// www.cortecostituzionale.it/actionSchedaPronuncia. do?anno=2014\&numero=162). En 2011, mientras la prohibición de la fecundación heteróloga aún se encontraba vigente, ${ }^{22}$ un informe oficial recomendaba, en términos muy vagos e imprecisos, reconocer el derecho del nacido, una vez alcanzada la mayoría de edad, de acceder a información sobre los propios orígenes. $^{15}$

\section{Argumentos o justificaciones para no revelar información}

Los argumentos que se han esgrimido para favorecen los modelos de no divulgación de la información

* El Tribunal Constitucional español en su sentencia 116/1999, de 17 de junio, terminó declarando constitucional la regla del anonimato adoptada por la Ley 35/1998. El derecho a la intimidad del donante no es un derecho absoluto, sino que cede ante el derecho a la vida y a la integridad física del nacido y ante el derecho a obtener la tutela judicial. El interés del donante en defender su anonimato es prevalente en el caso en que el nacido alegue un simple interés por conocer su origen biológico; puesto que, de lo contrario, no habría candidatos dispuestos a donar células reproductoras, lo que redundaría en la desprotección del derecho a la salud de las parejas estériles. El nacido siempre podrá consultar los datos no identificativos del donante, sin que la ocultación de la identidad del progenitor biológico sea razón suficiente para afirmar que se está violando la protección debido a los hijos conforme a la Constitución Española. de los donantes buscan preservar la conexión de los padres legales con los hijos pese a que no exista un vínculo genético con uno o ambos padres y facilitar que los niños se desarrollen con mayor estabilidad. Otro factor es no evidenciar que el hombre o mujer, o ambos, si son una pareja, padecen alguna disfunción reproductiva, situación que en algunas sociedades aún puede ser un estigma ${ }^{23-25}$ y busca preservar el derecho a la privacidad de los donantes.

Con relación con los argumentos en beneficio de los padres de intención, algunos estudios refieren que las razones por las cuales los padres deciden no informar a sus hijos sobre la forma en que fueron concebidos responden a la necesidad de evitar que puedan sentirse diferentes a otros miembros de la familia y el miedo a la irrupción del donante en la vida familiar. ${ }^{15}$

Respecto a los intereses del menor, algunos estudios indican que una relación genética no es esencial para una buena crianza social o para el desarrollo emocional satisfactorio de los niños, y que otorgar excesiva importancia a la genética no es la mejor manera de garantizar el bienestar de las familias que no se basan en ella. ${ }^{26}$ En todo caso, lo que se debe reconocer es el derecho de las personas nacidas con gametos o embriones provenientes de donadores, si así lo desean o lo requieren, a indagar sobre su verdadero origen genético.

Con relación con los intereses de los donantes se suele argumentar que es necesario preservar el anonimato para salvaguardar su derecho a la privacidad y confidencialidad, así como evitar posibles reclamaciones de paternidad. Previamente se señaló que la protección de los datos genéticos de los donadores puede verse limitada por la concurrencia de los derechos de terceros; sería el caso del derecho de los niños a conocer su verdadero origen y construir su propia identidad genética. Por otra parte, develar información de los donadores a los niños y niñas no conlleva reconocimiento de obligaciones filiales derivadas de este vínculo genético. Un adecuado marco legal deberá desvincular al donante de cualquier responsabilidad parental y de las obligaciones que el derecho les atribuye.

Es frecuente el argumento sobre que levantar el anonimato ocasionaría una disminución en el número de donaciones y daría lugar a mayores dificultades para la realización de estos procedimientos ante la 
falta de medios para concretarlos..$^{10,15,19,27^{* *}}$ Aunque el argumento indicado tuviera apoyo empírico, su encaje en el contexto de los derechos humanos es cuestionable, por tratarse de un argumento utilitarista. En los países escandinavos en donde el anonimato del donante ya no se preserva, después de una caída en las donaciones, el número de donantes se ha estabilizado. ${ }^{27}$

\section{Argumentos para revelar información}

Resulta fundamental partir por reconocer que quien dona su material genético lo hace en pleno ejercicio de su libertad, es decir, se coloca voluntariamente en esa situación, de modo que no parece irrazonable exigirle que asuma las consecuencias de su accionar..$^{10}$ En cambio, el niño concebido con gametos o embriones donados ha sido ajeno al acto por el cual se accedió a la procreación. ${ }^{18}$

En la actualidad, un sector de profesionales de la fertilidad se muestra a favor de revelar la identidad para formar relaciones familiares basadas en la honestidad ${ }^{28}$ y consideran que es perjudicial para cualquier relación entre dos personas, que una tenga información relevante sobre la otra, que no es divulgada, en especial dadas las consecuencias que puede tener descubrir esta información de forma accidental. Al respecto, Mary Warnock afirma que "ocultar esta información sería un caso obvio de negligencia hacia el bien del niño". ${ }^{27}$

Otra razón por la cual sería prudente abolir el anonimato consiste en el avance respecto al conocimiento del genoma de los progenitores ya que este constituye un componente importante en la garantía del derecho a la salud de los concebidos; los diagnósticos genéticos preimplantacionales pueden determinar el tratamiento de enfermedades o prevenirlas decisivamente; además de constituir información relevante al momento que el propio nacido de donación de gametos decida tener hijos. ${ }^{15,26}$

Si bien se puede afirmar que el menor tiene derecho a saber la verdad sobre su origen genético, no se puede establecer que sea una obligación conocerlo. Pero el derecho a no saber, como una manifestación

** En el Reino Unido un año después de que entrara en vigor la reforma que suprimió el anonimato del donante, se advirtió que las previsiones que auguraban una caída del número de donaciones no se cumplieron. En Suecia, un estudio realizado 15 años después de la entrada en vigor de la ley de 1984 muestra que no ha disminuido el número de donantes y los centros norteamericanos que ofrecen gametos procedentes de donantes que consienten ser identificados no tienen problema para reclutarlos. de libertad frente a saber, implica que ya se tiene conocimiento del hecho que genera este derecho. Por último, se argumenta que privar a una persona del conocimiento sobre su origen implica negarle uno de los elementos fundamentales que constituyen su identidad, a partir del cual se distingue de los demás y puede individualizarse en relación con aquellos de los que proviene. $6,10,19,28-30$

\section{Situación que prevalece en México}

En México, la expansión de los centros en los que se practican procedimientos de reproducción asistida y el elevado número de niños que han sido concebidos con ayuda estos revela la existencia de un mercado global. A pesar de lo anterior, hasta este momento no se cuenta con una regulación en la materia que norme los aspectos generales del acceso y provisión de los servicios de reproducción humana asistida. Debido a la ausencia de reglas claras, los responsables de las clínicas, tanto públicas como privadas, operan sus programas de donación de gametos y embriones con base en sus propios criterios, normas académicas o lineamientos emitidos en consenso por expertos en materia de infertilidad, lo que, independientemente del profesionalismo y calidad en la atención médica y científica, deja a los usuarios en situación de vulnerabilidad e incertidumbre jurídica.

\section{Situación normativa a nivel federal}

La emisión de la normatividad aplicable a los servicios de salud, específicamente respecto a los de reproducción humana asistida, es competencia federal y, con fundamento en el artículo 73 constitucional, corresponde a la Ley General de Salud establecer las bases para su regulación. El artículo 3 de dicha ley establece que el control sanitario de la disposición de órganos, tejidos y células es materia de salubridad general.

La regulación sobre el funcionamiento de los establecimientos públicos y privados donde se practican procedimientos de reproducción humana asistida, así como de los centros que operan como bancos de gametos compete a la Comisión Federal para la Protección contra Riesgos Sanitarios (Cofepris). Sin embargo, dentro de sus funciones no se encuentra realizar un registro sobre donantes, ni tampoco requiere a las clínicas a que lo generen.

Actualmente se encuentra en revisión en la Cámara de Diputados una minuta en materia de reproducción 
humana asistida. El dictamen avanza en proponer la creación de un Registro Nacional de Reproducción Asistida dependiente de la Secretaría de Salud federal, que funcionaría para recolectar información estadística sobre la práctica en México. ${ }^{31}$ En la misma legislatura se presentó otro dictamen de la Comisión de Salud de la Cámara de Diputados, que prohíbe el uso de semen de alguien distinto a la pareja, y no así de óvulos. ${ }^{32}$ En diciembre de 2017 se presentó otra iniciativa con el objeto de regular las TRHA, ${ }^{33}$ en esta se propone que la donación sea anónima y se garantice la confidencialidad de los datos de identidad de los donantes, y que se tenga derecho a obtener información general de los donantes de gametos y embriones solo en circunstancias extraordinarias que comporten un peligro cierto para la vida o la salud del hijo o cuando proceda con arreglo a las leyes procesales penales, podrá revelarse la identidad de los donantes al interesado (artículo 7.5). ${ }^{33}$

El artículo 36 de la iniciativa propone, atinadamente, la creación de un Registro Nacional de Donantes, cuya función sería inscribir, con base en los datos que proporcionen los establecimientos de salud, el registro de los donantes de gametos y embriones, con las garantías precisas de confidencialidad de los datos de aquellos, así como consignar los hijos nacidos de cada uno de los donantes, la identidad de las parejas o mujeres receptoras y la localización original de unos y otros en el momento de la donación y de su utilización. Las tres propuestas normativas deben ser discutidas y analizadas, puesto que contienen disposiciones que, de ser aprobadas, podrían vulnerar derechos humanos. ${ }^{34}$

\section{Situación en las clínicas y establecimientos que realizan TRHA con gametos o embriones donados}

En el ámbito público, el Centro Médico Nacional "20 de Noviembre" (del Instituto de Seguridad y Servicios Sociales de los Trabajadores del Estado), el Hospital Materno-Perinatal "Mónica Pretelini" (que pertenece al Instituto de Salud del Estado de México) y el Instituto Nacional de Perinatología cuentan con un programa de biología de la reproducción humana y realizan técnicas reproductivas de alta complejidad; sin embargo, debido a la falta de un adecuado marco legal, se ven imposibilitados para efectuar TRHA con gametos y embriones de donadores. ${ }^{35}$ El Instituto Nacional de Perinatología es la única institución que realiza procedimientos con semen proveniente de donantes -no así óvulos y embriones-, pero los gametos son provistos por bancos externos. ${ }^{35}$

En el sector privado, debido a que no existe una autoridad sanitaria responsable de requerir y publicar los datos que generen los establecimientos de salud autorizados para practicar TRHA, es difícil obtener datos e información sobre la práctica y el funcionamiento de los programas de donantes. La información disponible en internet demuestra que la donación se realiza con base en contratos confidenciales entre los donantes y los centros autorizados. ${ }^{36-47}$ La información de los donantes, receptores y de los niños que podrían resultar de estos procedimientos permanece bajo el más estricto anonimato. Los donantes solo podrán ser contactados por el centro responsable en caso de que la salud del niño lo requiera, para ello el centro se compromete a conservar indefinidamente la información de los donantes. ${ }^{48}$ Los centros que hacen alguna referencia a esta posibilidad de contacto, aclaran que este será entre la clínica y el donante, no así entre los padres legales o el hijo que requiere la información. Algunos sitios web, los más completos, señalan que constantemente renuevan su base de donantes de semen y limitan el número de embarazos que se consiguen con cada muestra para evitar el riesgo de endogamia entre hijos de pacientes diferentes con un donante en común. De lo anterior se advierte que, pese a que no existe una normativa que regule a la donación de gametos y embriones en México, la práctica se rige bajo las reglas de la confidencialidad y el anonimato.

\section{El derecho de los menores a conocer a su origen genético en la normativa nacional}

El principio del interés superior del niño encuentra fundamento en el párrafo octavo del artículo 4 de la Constitución Política de los Estados Unidos Mexicanos, y en el artículo 3, apartado 1, de la Convención sobre los Derechos del Niño (ratificada por México el 21 de septiembre de 1990 y publicada en el Diario Oficial de la Federación del 25 de enero de 1991), de donde se advierte que en cualquier decisión, actuación o medida que involucre a la niñez, el Estado tiene la ineludible obligación de atender a su interés superior.

Aun cuando el precepto constitucional dentro del que se comprenden los derechos de la niñez no hace referencia al derecho a la identidad de los menores, su ley reglamentaria, la Ley para la Protección de los Derechos de Niñas, Niños y Adolescentes, establece 
como partes integrantes del derecho a la identidad, entre otros, conocer su filiación y su origen, que en su artículo 22, indica:49

\begin{abstract}
El derecho a la identidad está compuesto por: A. Tener un nombre y los apellidos de los padres desde que nazca y a ser inscrito en el Registro Civil; B. Tener una nacionalidad, de acuerdo con lo establecido en la Constitución; C. Conocer su filiación y su origen, salvo en los casos que las leyes lo prohíban; D. Pertenecer a un grupo cultural y compartir con sus integrantes costumbres, religión, idioma o lengua, sin que esto pueda ser entendido como razón para contrariar ninguno de sus derechos. A fin de que niñas, niños y adolescentes puedan ejercer plenamente el derecho a su identidad, las normas de cada entidad federativa podrán disponer lo necesario para que la madre y el padre los registren, sin distinción en virtud de las circunstancias de su nacimiento.
\end{abstract}

Por su parte, la Suprema Corte de Justicia de la Nación (SCJN) se ha pronunciado sobre el derecho a la identidad de los niños, al señalar que este se compone por el derecho a tener un nombre y los apellidos de los padres desde que nacen, a tener una nacionalidad, a conocer su filiación y origen y a tener certeza de quién es su progenitor, lo que constituye un principio de orden público. ${ }^{50}$ También ha resuelto que el derecho a la identidad constituye un derecho de los niños y no una facultad de los padres, y si bien la tendencia es que la filiación jurídica coincida con la filiación biológica, ello no siempre es posible, ya sea por la propia realidad del supuesto hecho o porque el ordenamiento hace prevalecer otros intereses que se consideran jurídicamente más relevantes, como podría ser la filiación adoptiva y las procreaciones asistidas por donación de gametos. ${ }^{51}$ Recientemente sostuvo que el derecho a la identidad en su vertiente de conocimiento de los nexos biológicos de una persona está relacionado con el desarrollo adecuado de la personalidad, el derecho a la salud mental, así como con el derecho a conocer la información médica relevante derivada de las características genéticas propias. La relación de filiación no es una consecuencia necesaria del establecimiento de la verdad biológica, por lo que puede permitirse a una persona la indagatoria respecto a sus orígenes biológicos sin que necesariamente ello conlleve un desplazamiento filiatorio. ${ }^{52}$

\section{A nivel local}

Han sido las legislaciones locales las que, en los códigos civiles o familiares han incluido algunas regulaciones sobre procedimientos de reproducción asistida, en particular lo concerniente al estado civil de las personas fruto de esos avances científicos. Sobre la investigación de la paternidad en procedimientos de reproducción humana asistida, ya se han pronunciado los estados de Sonora y México, con posiciones opuestas.

El Código de Familia para el Estado de Sonora prevé que el hijo puede solicitar, al llegar a su mayoría de edad, informes sobre el padre biológico en los mismos casos que en la adopción plena, sin reclamar ningún derecho filiatorio, En el artículo 207 indica:53

\begin{abstract}
Cuando el embarazo se obtenga por técnicas de reproducción asistida con material genético de personas distintas de uno 0 ambos cónyuges o concubinos, los que usen voluntariamente gametos de terceros serán considerados como padres biológicos del niño que nazca por estos métodos, siempre que hayan otorgado expresamente su autorización. El hijo podrá solicitar, al llegar a su mayoría de edad, informes sobre el padre biológico en los mismos casos que en la adopción plena, sin reclamar ningún derecho filiatorio.
\end{abstract}

No deja claro qué tipo de información se puede obtener de los donantes o incluso si es viable conocer su identidad; sin embargo, el numeral remite al apartado que regula la adopción plena. Al respecto, el código familiar de ese Estado prevé la prohibición de informar sobre los antecedentes registrales del adoptado, a no ser que él mismo lo solicite cuando llegue a la mayoría de edad, previa autorización judicial, con los fines de conocer íntegramente su identidad o proteger su salud a través del conocimiento de posibles enfermedades hereditarias o a petición del Ministerio Público, en los casos de investigación criminal (artículo 300). ${ }^{53}$

\begin{abstract}
Hasta el momento, el poder judicial de ese Estado no ha resuelto asuntos en los que la litis verse sobre el derecho del menor a conocer la identidad del donante, en términos de lo previsto por el Código de Familia. ${ }^{54}$ La ausencia de juicios en esa entidad probablemente se deba a que existen pocas clínicas, al menos con registro ante Cofepris, aunado a que su apertura es relativamente reciente; sin embargo, eventualmente las autoridades podrían conocer de controversias sobre esta cuestión. Si bien se avanza en el sentido de abrir la posibilidad de que el hijo, al llegar a la mayoría de edad, pueda solicitar información sobre los donantes que aportaron su material genético, la ausencia de normativa en la materia que obligue a los responsables de bancos o clínicas a conservar la información y la falta de registros de donantes pueden generar que los posibles interesados se enfrenten a la situación de que la clínica no cuente con la información del donante o que esta no siga operando, en cuyo caso sería materialmente imposible ejercer tal derecho.
\end{abstract}

Por otra parte, el Código Civil del Estado de México prohíbe en los casos en que la inseminación artificial se efectúe con esperma -no prevé el supuesto de ovocitos ni embriones- proveniente de bancos 0 
instituciones legalmente autorizadas a revelar el nombre del donante ni habrá lugar a investigación de la paternidad (artículo 4.115). ${ }^{55}$

Se considera que esta prohibición tiene consecuencias jurídicas: ¿qué pasaría si esta información fuera necesaria para efectos de salvaguardar la salud de la persona nacida con ayuda de material genético donado o bien para garantizar el derecho a conocer su identidad genética?

Actualmente, la norma oficial mexicana sobre el expediente clínico obliga a las instituciones o prestadores del servicio médico a conservar la información y datos de los pacientes por un período mínimo de cinco años. ${ }^{56}$ Prevé que los expedientes clínicos son propiedad de la institución o del prestador de servicios médicos que los genera, cuando este no dependa de una institución. Las instituciones del sector público, además de lo establecido en esta norma, deberán observar las disposiciones que en la materia estén vigentes. Sin perjuicio de lo anterior, el paciente, en tanto aportante de la información y beneficiario de la atención médica, tiene derechos de titularidad sobre la información para la protección de su salud, así como para la protección de la confidencialidad de sus datos, en los términos de esta norma y demás disposiciones jurídicas que resulten aplicables. Por lo anterior, por tratarse de documentos elaborados en interés y beneficio del paciente, deberán ser conservados por un periodo mínimo de cinco años, contados a partir de la fecha del último acto médico. ${ }^{56}$

Evidentemente el plazo que prevé la norma oficial mexicana para resguardar el expediente clínico resultaría insuficiente frente a una eventual solicitud del hijo para obtener información sobre sus progenitores genéticos. Adicionalmente, existe una la ley federal que protege los datos personales en posesión de particulares, ${ }^{57}$ a efecto de garantizar la privacidad de las personas. La normativa prevé que serán datos sensibles aquellos que afectan la esfera más íntima de su titular toda vez que revelan aspectos como el origen racial o étnico, el estado de salud presente y futuro, la información genética, las creencias religiosas, entre otras; sería el caso de la información que proporcionan los donantes a los responsables de las clínicas. En su artículo 3.6 señala lo siguiente:57

\footnotetext{
Para los efectos de esta Ley, se entenderá por: Datos personales sensibles: Aquellos datos personales que afectan a la esfera más íntima de su titular, o cuya utilización indebida pueda dar origen a discriminación o conlleve un riesgo grave para éste. En particular, se consideran sensibles aquellos que puedan revelar aspectos como origen racial o étnico, estado de salud presente y futuro, información genética,
}

creencias religiosas, filosóficas y morales, afiliación sindical, opiniones políticas, preferencias sexuales.

A pesar de que esta ley establece que los principios de derecho previstos tendrán como límite en cuanto a su observancia y ejercicio, la protección de los derechos de terceros (artículo 4); 57 sería conveniente que al aprobarse la ley que regule la reproducción humana asistida en México, se considere como excepción el derecho de un menor a obtener información del donante en aras de proteger su derecho a conocer su identidad genética.

En definitiva, ante una colisión entre derechos lo deseable sería buscar armonizarlos, sin embargo, en un asunto como en el que nos ocupa, para no dejar sin protección el derecho a la identidad del menor, resulta inevitable buscar una vía jurídica que los evalúe y pondere justamente, debiendo dilucidar cuál resulta superior o más valioso, o si es constitucional restringir algún derecho fundamental en función de una finalidad concreta y, en ese sentido, resolver el conflicto. ${ }^{58}$

\section{Consideraciones finales}

De lo expuesto, se concluye que el derecho a la identidad en su vertiente del conocimiento del origen genético de una persona está relacionado con el desarrollo adecuado de la personalidad, el derecho a la salud, así como con el derecho a conocer la información médica relevante derivada de las características genéticas propias. Sin embargo, debe quedar claro que la relación de filiación no es una consecuencia necesaria del establecimiento del origen genético; por lo que, si bien debe permitirse a una persona la indagatoria respecto a sus orígenes genéticos, ello no conlleva un desplazamiento filiatorio, así como obligaciones y responsabilidades parentales para las personas de quienes procede el material genético donado.

Se comparte la opinión de especialistas que consideran conveniente que los procedimientos de reproducción asistida heterólogos no operen bajo los principios del secreto, anonimato y confidencialidad, esto se apoya en la idea de que es la protección del interés superior del niño y la niña a conocer sus orígenes genéticos, lo que debe dirigir el enfoque jurídico.

Hasta este momento, México no cuenta con un marco regulatorio que norme los aspectos generales del acceso y provisión de los servicios de reproducción humana asistida. Han sido algunas legislaciones locales las que, en los códigos civiles o familiares, han incluido aspectos sobre estos procedimientos, en 
particular al estado civil de las personas fruto de esos avances científicos, es el caso de Sonora, que si bien faculta al hijo, al llegar a la mayoría de edad, a solicitar información sobre los donantes que aportaron su material genético, la ausencia de normativa en la materia que obligue a los responsables de bancos o clínicas a conservar la información y la falta de registros de donantes pueden generar que los interesados se enfrenten a que la clínica no cuente con la información requerida o que no siga operando, en cuyo caso sería imposible ejercer tal derecho.

Por ello es necesario se discuta de manera multidisciplinaria la emisión de marco normativo que regule la actuación médico-científica y ética del personal de salud y de los establecimientos que realizan procedimientos de reproducción humana asistida. Se considera conveniente prever la creación de un registro nacional de donantes, dependiente de la Secretaría de Salud federal, cuya función sería el registro de los donantes de gametos y embriones, con base en la información que proporcionen los responsables de los establecimientos autorizados para practicar procedimientos de reproducción asistida.

Este registro único permitiría consignar los hijos nacidos de cada uno de los donantes, para evitar el riesgo de endogamia entre hijos de pacientes diferentes con un donante en común; la identidad de las parejas o mujeres receptoras y la localización original de unos y otros en el momento de la donación y de su utilización; garantizar el acceso a la información a las personas que han nacido producto de estas donaciones y a su vez consignar garantías precisas de confidencialidad de los donadores frente a personas que no acrediten un interés jurídico legítimo.

\section{Bibliografía}

1. Zegers-Hochschild F, Adamson D, Dyer S, Racowsky C, De-Mouzon J Sokol R, et al. The international glossary on infertility and fertility care, 2017. Fertil Steril. 2017;108:393-406.

2. Harper JC, Kennett D, Reisel D. The end of donor anonymity: how genetic testing is likely to drive anonymous gamete donation out of business. Hum Reprod. 2016;31:1135-1140.

3. Nahata L, Stanley N, Quinn G. Gamete donation: current practices, public opinion, and unanswered questions. Fertility Steril. 2017;107:1298-1299.

4. Kemelmajer-De-Carlucci AR. Origen biológico, derecho a conocer. En Romeo-Casabona CM, director. Enciclopedia de bioderecho y bioética. España: Cátedra Interuniversitaria/Fundación BBVA/Diputación foral de Bizkaia/Universidad de Deusto/Universidad del País Vasco; 2018.

5. International Federation of Fertility Societies. IFFS surveillance 2016. Global Reprod Health. 2016;e1:1-143.

6. González-Contró M. Reflexiones sobre el derecho a la identidad de niñas, niños y adolescentes en México. Bol Mex Derecho Comp. 2011;44 107-133.

7. Suprema Corte de Justicia de la Nación. Interés superior de los menores de edad. Necesidad de un escrutinio estricto cuando se afectan sus intereses. En: Tesis jurisprudencial P./J.7/2016 (10 $)$, pleno de la Suprema Corte de Justicia de la Nación, 23 de septiembre de 2016 (acciones de inconstitucionalidad). Gaceta del Semanario Judicial de la Federación, décima época, libro 34, tomo 1, septiembre 2016, p.10. Disponible en: https://www.scjn.gob.mx/sites/default/files/gaceta/documentos/tomos/2016-12/libro34t1.pdf

8. Muñoz-Genestoux R, Vittola LR. El derecho a conocer el origen genético de las personas nacidas mediante técnicas de reproducción humana asistida con donante anónimo. Rev IUS. 2016;11:207-227.

9. Brena-Sesma I. Privacidad y confidencialidad de los datos genéticos. Bol Mex Derecho Comp. 2008;número conmemorativo:109-125.

10. Gómez-Sánchez Y. El derecho a la reproducción humana. Madrid, España: Marcial Pons; 1994

11. Théry I. El anonimato en las donaciones de engendramiento: filiación e identidad narrativa infantil en tiempos de descasamiento. Rev Antropol Soc. 2009:18:21-42.

12. Sánchez-Martínez MO. Los orígenes biológicos y los derechos de hijos e hijas: filiación y derecho a saber. Cuad Electron Filos Derecho. 2016;34:294-315

13. Aguilar-Cavallo G. El principio del interés superior del niño y la Corte Interamericana de Derechos Humanos. Cent Estud Consti Chile. 2008;6:223-247.

14. Comité de los Derechos del Niño. Convención sobre los Derechos del Niño. Reino Unido: Naciones Unidas; 2002.

15. Alkorta-Idiakez I, Farnós-Amorós E. Anonimato del donante y derecho a conocer: un difícil equilibrio. Oñati Socio-legal Series. 2017;7:148-178.

16. Corte Interamericana de Derechos Humanos. Caso de las hermanas Serrano Cruz vs El Salvador. Sentencia de 1 de marzo de 2005. Costa Rica: Corte Interamericana de Derechos Humanos; 2005.

17. Ory SJ, Devroey P, Banker M, Brinsden P, Buster J, Fiadjoe M, et al. IFFS Surveillance 2013. EE. UU.: International Federation of Fertility Societies; 2013

18. Famá MV. El derecho a la identidad del hijo concebido mediante técnicas de reproducción humana asistida en el proyecto de código civil y comercial de la nación. Lecciones y Ensayos. 2012;90:171-195.

19. Frith L. Gamete donation and anonymity. The ethical and legal debate, Hum Reprod. 2001;16:818-824.

20. Turkmendag I. The donor-conceived child's "right to personal identity": the public debate on donor anonymity in the United Kingdom. J Law Soc. 2012;39:58-72.

21. Pennings G. The "double track" policy for donor anonymity. Hum Reprod. 1997; 12:2839-2844

22. Corn E. La reproducción humana asistida en Italia. Presente y futuro después de la derogación de la prohibición de fecundación heteróloga. Rev Bioet Derecho. 2015;35:18-31

23. Barbieri RL. Female infertility. En: Strauss J, Barbieri R. Yen and Jaffe's reproductive endocrinology. Physiology, pathophysology, and clinical management. EE. UU.: Elsevier/Saunders; 2006.

24. World Health Organization [Sitio web]. Infertility definitions and terminology. Suiza: World Health Organization; 2019. Disponible en: https:// www.who.int/reproductivehealth/topics/infertility/definitions/en

25. Larsen U. Research on infertility: which definition should we use? See comment in PubMed Commons belowFertil Steril. 2005;83:846-852.

26. De Melo-Martin I. How best to protect the vital interests of donor-conceived individuals: prohibiting or mandating anonymity in gamete donations? Reprod Biomed Soc Online. 2016;3:100-108.

27. Warnock M. Fabricando bebés, ¿existe un derecho a tener hijos? España: Gedia; 2004

28. Igareda-González N. El derecho a conocer los orígenes biológicos versus el anonimato en la donación de gametos. Rev Instit Bartolomé de as Casas. 2014;31:227-249.

29. Corral-Talciani $\mathrm{H}$. Intereses y derechos en colisión sobre la identidad del progenitor biológico: Los supuestos de la madre soltera y del donante de gametos. lus et Praxis. 2010:16:57-87.

30. Vidal-Prado C. El derecho a conocer la filiación biológica (con especial atención a la filiación materna). Rev Jurid Navarra.1996;22:265-282.

31. Iniciativa que reforma y adiciona diversas disposiciones de la Ley General de Salud, a cargo de la diputada Maricela Contreras Julián, del grupo parlamentario del PRD. Gaceta Parlamentaria, año 18, número 4398-II, miércoles 4 de noviembre de 2015 .

32. Iniciativa que reforma y adiciona diversas disposiciones de la Ley General de Salud, a cargo de la diputada Sylvana Beltrones Sánchez, de grupo parlamentario del PRI. Gaceta Parlamentaria, Número 4479-IV, 1 de marzo de 2016.

33. Iniciativa con proyecto de decreto que reforma el artículo 73 de la Constitución Política de los Estados Unidos Mexicanos y expide la Ley General de Técnicas de Reproducción Asistida, a cargo de la diputada Liliana Ivette Madrigal Méndez, del grupo parlamentario del PRI. (Consultada 2018 Feb 10). Disponible en: http://sil.gobernacion.gob.mx/Archivos/Documentos/2017/12/asun_3639908_20171206_1512505579.pdf.

34. Palacios-González C. Una ley que prohíbe embarazos y trasplantes. Animal Político [Sitio web]. Sección El Plumaje. México: 2016 Dec 14. Disponible en: animalpolitico.com/blogueros-una-vida-examinada-reflexiones-bioeticas/2016/12/14/una-propuesta-ley-prohibe-embarazos-trasplantes.

35. Sistema de Acceso a la Información Pública: Infomex folios: 0063700717317 , 1225000029017. Saimex: 0057/IXEM/IP/2017. 
36. Clínica IN-FIV. [Sitio web]. (Consultado 2017 Oct 17). Disponible en: http://www.clinicainfertilidadtoluca.com/index.html.

37. Inmater, [Sitio web]. (Consultado 2017 Oct 17). Disponible en: http:// inmater.com/banco-de-ovulos.

38. Embryofertyl, [Sitio web]. (Consultado 2017 Oct 17). Disponible en: https://www.embriofertyl.com.mx/banco-de-semen-donacion.

39. Instituto Ingenes, [Sitio web]. (Consultado 2018 Feb 06). Disponible en https://www.ingenes.com/donacion/programa-de-donacion-de-ovulos.

40. Viltis. [Sitio web]. (Consultado 2018 Nov 06). Disponible en: viltis.com. $\mathrm{mx} /$ donacion-de-ovulos-ovodon.

41. Centro Mexicano de Fertilidad, Dr. Alberto Kably. [Sitio web]. (Consultado 2018 Feb 21). Disponible en: http://kablyfertilidad.com/conociendo-alternativas/fivte.

42. Concibe. [Sitio web]. (Consultado 2018 Feb 06). Disponible en: http:// www.concibe.com.mx/informacion-para-donantes-de-semen.

43. Biofertility Center AIM. [Sitio web]. (Consultado 2018 Feb 21). Disponible en: http://www.biofertilitycenter.com/index.php/es/donacion-de-ovulos.

44. NASCERE. [Sitio web]. (Consultado 2018 Feb 21). Disponible en: http:// nascere.com.mx/servicios/programa-de-donacion-ovular.

45. PROCREA. [Sitio web]. (Consultado 2108 Feb 21). Disponible de: http:// www.procrea.mx/es/servicios.

46. Instituto Vida. [Sitio web]. Disponible en: http://www.institutovidamexico. com.mx/donacionovulos.html.

47. Fertility Center Cancún. [Sitio web]. (Consultado 2018 Feb 20). Disponible en: http://www.fertilitycentercancun.com.mx/donacion-esperma.html.

48. Instituto Ingenes. [Sitio web]. Dudas y temores sobre la donación. Consultado 2018 Feb 06. Disponible en: https://www.ingenes.com/donacion/ programa-de-donacion-de-ovulos/.

49. Secretaría de Gobernación. Ley para la protección de los derechos de niñas, niños y adolescentes. México: Diario Oficial de la Federación
2000 May 29. Disponible en https://www.dof.gob.mx/nota detalle.php?codigo $=2055514 \&$ fecha $=31 / 12 / 1969$.

50. Tesis aislada 1a. CXLII/2007. Rubro: Derecho a la identidad de los menores. su contenido, publicada en el Semanario Judicial de la Federación y su Gaceta, Novena Época, Tomo XXVI, julio de 2007, Materia Civil, p. 260.

51. Tesis aislada 1a. CCCXXI/2014 (10a.). Rubro: Filiación. alcances y límites del principio de verdad biológica. Gaceta del Semanario Judicial de la Federación, décima época, Tomo I, libro 10, septiembre de 2014, Materia Constitucional, Civil, p. 577.

52. Tesis Aislada $1^{a}$ LXIX. Rubro: Derecho a la identidad biológica. la restricción legal al cambio filiatorio no implica la prohibición de indagar la paternidad de una persona (interpretación del art. 377 del código civil para el estado de colima). Seminario Judicial de la Federación, Décima Época, 15 de junio 2018, materia Constitucional, civil.

53. Código de Familia para el Estado de Sonora. México: Congreso del Estado de Sonora; 2007.

54. Sistema de Acceso a la Información Pública: Infomex, folio 00940617.

55. Código Civil del Estado de México. México: Congreso del Estado de México; 2002

56. Secretaría de Salud. Norma Oficial Mexicana NOM-004-SSA3-2012, del expediente clínico. México: Diario Oficial de la Federación 2012 Jun 29. Disponible en: http://dof.gob.mx/nota_detalle_popup.php?codigo=5272787.

57. Secretaría de Gobernación. Ley Federal de Protección de Datos Personales en Posesión de los Particulares. México: Diario Oficial de la Federación 2010 Jul 05. Disponible en: https://www.dof.gob.mx/nota_detalle.php?codigo $=5150631 \&$ fecha $=05 / 07 / 2010$.

58. Tello-Moreno LF. Pruebas de ADN y presunción de la paternidad en los juicios de filiación. Derechos Hum Mex. 2006;2:225. 